\title{
Penggantian Shock Absorber pada Honda CRV I-VTEC type RE1 di PT. X Surabaya Shock Absorber Replace on Honda CRV I-VTEC type RE1 in PT. X Surabaya \\ Ahmad Khusnul Hidayat ${ }^{1}$, Firman Yasa Utama ${ }^{2}$ \\ Jurusan Teknik Mesin, Fakultas Teknik, Universitas Negeri Surabaya \\ firmanutama@unesa.ac.id
}

\begin{abstract}
Abstrak--Honda CRV adalah salah satu tipe kendaraan SUV (Sport Utility Vehicle) tipe penggeraknya berjenis Front Engine Front Drive (FF) yang penempatan mesin dan roda penggerak utamanya berada di bagian depan. Dikarenakan beban terfokus pada satu titik yaitu didepan maka perawatan pada komponen understell sangat perlu diperhatikan khususnya pada bagian shock absorber. Penggantian shock absorber pada mobil Honda CRV dikarenakan BB (bunyi-bunyi) dalam kategori servis dengan 16 langkah pengerjaan. Agar menghindari kerusakan yang lebih parah, monitoring dan perawatan rutin sesuai petunjuk dan kondisi penggunaan menjadi faktor penting agar komponen selalu mengalami kondisi prima.
\end{abstract}

Kata Kunci : Honda CRV, shock absorber, SUV, understell, bunyi-bunyi

Abstract---Honda CRV is one vehicle type SUV (Sport Utility Vehicle) with driving-type Front Engine Front Drive (FF) the placement of the engine and its wheel drive. Due to the focused on a single point load in front of the then the treatments on the component understell is very noteworthy in particular shock absorber. Replacement shock absorbers on cars Honda CRV cause BB (bunyi-bunyi). Penggantian shock absorber pada mobil Honda CRV dikarenakan BB (bunyi-bunyi) in the category of services with 16 step workmanship. dalam kategori servis dengan 16 langkah pengerjaan. In order to avoid more severe damage, monitoring and routine maintenance according to the instructions and conditions of use be an important factor in order for the components always have top condition

Keyword : Honda CRV, shock absorber, SUV, understell, bunyi-bunyi

\section{Pendahuluan}

Honda CRV adalah salah satu tipe kendaraan SUV (Sport Utility Vehicle) merupakan gabungan jeep, pick up dan sedan. Desainya memiliki ground clearance (jarak bodi mobil ke tanah) yang tinggi. Sedangkan tipe penggeraknya berjenis Front Engine Front Drive (FF) yang penempatan mesin dan roda penggerak utamanya berada di bagian depan. Sistem suspensi menggunakan tipe independent, setiap roda dapat bergerak secara sendiri-sendiri sesuai dengan respon dan kondisi jalan. Salah satu kelemahan dari tipe penggerak ini berat kendaraan terdapat di bagian depan. Hal ini membuat pengendalian mobil di kecepatan tinggi saat mobil berisi penuh penumpang, sedikit lebih susah dikendalikan. Oleh karena itu peran suspensi sangat menentukan keamanan, kenyamanan, dan stabilitas kendaraan di berbagai medan. Pola perawatan yang terprogram sesuai jarak tempuh menjadi salah satu yang wajib diperhatikan. Dikarenakan beban terfokus pada satu titik yaitu didepan maka perawatan pada komponen understell sangat perlu diperhatikan khususnya pada bagian shock absorber.

\section{TEORI}

Sistem suspensi adalah suatu bagian dari chasis yang berfungsi menyerap kejutan dari jalan agar tidak tersalur ke bodi, serta untuk menambah kenyamanan berkendara. Secara umum setiap sistem suspensi terdiri dari lengan yang dihubungkan ke bodi dan roda untuk menentukan hubungan posisi keduanya. Dilengkapi pegas yang berfungsi untuk meredam getaran atau benturan yang berasal dari permukaan jalan, sedangkan damper yang berfungsi untuk mengontrol pergerakan pegas. Fungsi lain dari suspensi itu sendiri yaitu : a) menyerap getaran, oskilasi dan kejutan akibat pengaruh dari permukaan jalan yang tidak rata; b) memindahkan gaya pengereman dan gaya gerak ke bodi; c) menopang bodi pada axle dan memelihara letak geometris antara roda. Sistem suspensi dapat dibagi dua berdasarkan rancangannya, yaitu : tipe rigid axle dan tipe independent.

Pada tipe rigid axle, roda kiri dan kanan dihubungkan dengan as roda tunggal dan beban yang di arahkan ke roda di tunjang oleh as roda tersebut. Suspensi rigid axle lebih efektif untuk mempertahankan suatu benturan suspensi yang besar pada kendaraan yang memiliki variasi beban yang beragam sebagai akibat dari perubahan berat kargo atau jumlah penumpang. Sifat-sifat suspensi rigid axle : a) Gerakan salah satu roda mempengaruhi roda yang lain; b) Kontruksinya sederhana perawatannya mudah; c) Memerlukan ruang pemegasan yang besar

Tipe independent, tidak terdapat as roda yang menghubugkan roda kiri dan kanan, beban yang di arahkan ke roda-roda di topang oleh suspension arm. Karenanya, setiap roda dapat bergerak secara sendiri-sendiri sesuai dengan respon dan kondisi jalan sehingga memiliki rancangan yang lebih rumit daripada tipe rigid axle namun roda memiliki kontak dengan permukaan jalan yang lebih baik. Adapun sifatsifat Suspensi Independent : a) Gerakan salah satu roda tidak 
mempengaruhi gerakan roda lain; b) Kontruksinya agak rumit; c) Perawatan lebih sulit; d)Membutuhkan sedikit tempat.

Kendaraan Honda pada umumnya menggunakan suspensi tipe independent. Ada dua macam model, double wishbone, dan model kedua MacPherson strut yang digunakan honda CRV. Kelebihan model MacPherson strut sederhana yang terdiri dari sebuah lower arm dan sebuah rangkaian damper. Rangkaian damper sendiri terdiri dari sebuah shock absorber dan sebuah pegas coil yang biasa disebut strut. Selain itu dengan rangkaian yang ringan membuat pemasangan dan perawatan yang mudah, sehingga spring mass dapat dikurangi. Rangkaian damper (strut) menahan kekuatan eksternal non-vertikal, yang mengakibatkan meningkatnya pergesekan damper. Untuk mengurangi gesekan ini, pegas diposisikan sedemikian rupa sehingga poros longitudinal tidak parallel dengan poros damper.

Apabila pada suspensi hanya terdapat pegas, kendaraan akan cenderung beroskilasi naik turun pada waktu menerima kejutan dari jalan. Akibatnya berkendaraan menjadi tidak nyaman untuk itu shock absorber dipasang untuk meredam oskilasi dengan cepat agar memperoleh kenikmatan berkendaraan dan kemampuan cengkeram ban terhadap jalan. Di dalam shock absorber telescopic terdapat cairan khusus yang disebut minyak shock absorber. Pada shock absorber tipe ini, gaya redamnya dihasilkan oleh adanya tahanan aliran minyak karena melalui orifice (lubang kecil) pada waktu piston bergerak.

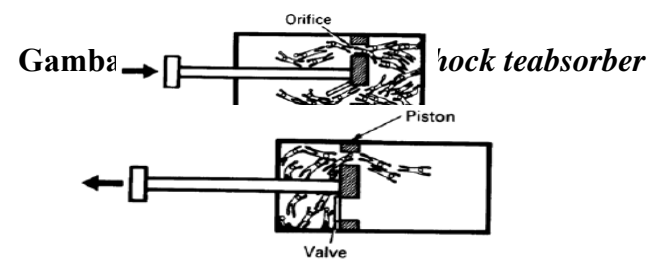

Gambar 2. Ekspansi dalam shock absorber

Sedangkan tipe penggerak roda yang meneruskan tenaga putar dari engine (melalui proses pembakaran) dan diteruskan ke roda melalui komponen-komponen yang tergabung pada sistem power train (sistem pemindah daya). Dalam rancangannya, power train ini dibagi dalam beberapa tipe, FF (Front Engine Front Drive), FR (Front Engine Rear Drive), RR (Rear Engine Rear Drive) serta FWD (Front Wheel Drive) atau AWD (All Wheel Drive). Honda CRV adalah salah satu tipe kendaraan SUV (Sport Utility Vehicle) berjenis Front Engine Front Drive (FF) yang penempatan mesin dan roda penggerak utamanya berada di bagian depan.

Paket servis merupakan suatu paket perawatan yang di tawarkan oleh Honda untuk customer, perawatan ini menekankan pada perawatan minimum yang diperlukan untuk memastikan agar kendaraan bebas dari gangguan selama digunakan. Macam-macam paket servis:

a. Paket PMB (Packet Manual Book)

Paket yang dilakukan sesuai jadwal dengan buku manual yang telah disediakan oleh Honda

b. Paket Cermat
Paket yang ditawarkan oleh Honda dengan biaya yang lebih murah

c. Paket FS (Free Servis)

Paket yang ditawarkan oleh Honda dengan biaya jasanya 0 , tetapi untuk biaya spare part nya tetap dikenakan biaya

d. Paket Perawatan Berkala (KM)

Paket yang dilakukan sesuai jadwal yang lebih dahulu tercapai dalam hal jarak tempuh atau kilometernya (Paket $20.000,40.000,60.000,80.000,100.000)$ sesuai dengan kelipatannya

Honda di PT. X mempunyai 3 bidang dalam hal service yaitu quick sercive (servis cepat), general repair (perbaikan umum), dan body repair (perbaikan body). Quick service (servis cepat) yaitu perbaikan kendaraan yang bersifat ringan dengan mengutamakan efisiensi waktu sehingga waktu pengerjaan cepat seperti cek rem 4 roda, ganti oli mesin + filter oli + oli transmisi, service berkala dengan paket ganjil, membersihkan throttle body. General repair (perbaikan umum) yaitu perbaikan yang bersifat umum atau menyeluruh mulai dari paket $20.000 \mathrm{~km}$ hingga $120.000 \mathrm{~km}$ dan perbaikan berat seperti perbaikan kelistrikan, penggantian komponen dalam mesin dan lain lain. Dan yang terakhir body repair (perbaikan body kendaraan) yaitu perbaikan yang dilakukan menyangkut pada body kendaraan seperti pengecatan body mobil dan penggantian rangka mobil.

Proses perawatan komponen-komponen suspensi terutama pada shock absorber dan bearing roda pada mobil Honda CRV termasuk pada paket perawatan berkala. Adapun data selama Oktober 2018 di PT X sebagai berikut :

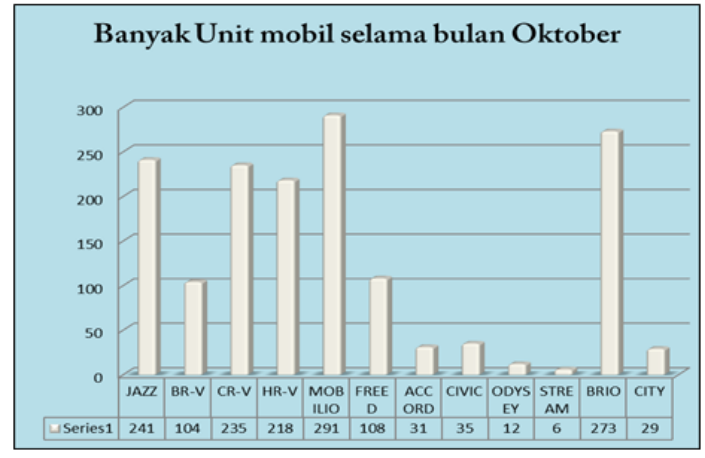

Gambar 3. Jumlah Unit Mobil Dalam Bulan Oktober

Selama sebulan kurang lebih 1583 unit mobil yang masuk dengan 12 tipe mobil honda yang sering melakukan perbaikan ataupun servis berkala. Honda Jazz, Br-v, Cr-v, Hr-v, Mobilio, Freed, Accord, Civic, Odysey, Stream, Brio, City. Dari banyaknya mobil yang masuk, Honda Mobilio, Brio, dan Jazz menjadi mobil urutan tertinggi yang sering mengalami perbaikan, baik dalam hal penggantian spare part ataupun dalam hal servis berkala. Dengan banyaknya unit yaitu Honda Mobilio (291 unit), Honda Brio (273 unit), dan Honda Jazz (241 unit). 


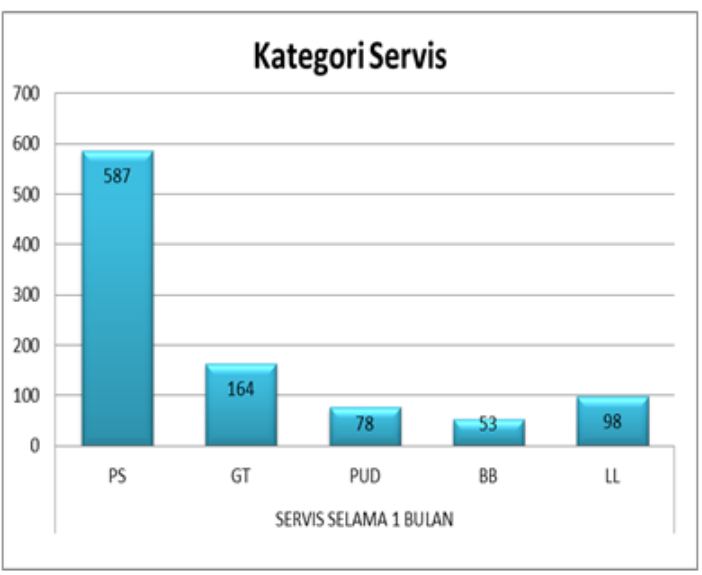

Gambar 4. Kategori Servis

Dari gambar diatas dapat dilihat kategori servis dapat digolongkan menurut beberapa kerusakan seperti Ps (paket servis), Gt (ganti), Pud (part update), BB (bunyi-bunyi), dan LL (lain-lain). Selama 1 bulan, kategori servis yang sering dilakukan diurutan tertinggi yaitu Ps (paket servis) sebanyak 587 unit mobil yang masuk, dimana dalam paket servis ini terdapat banyak macam, seperti paket manual book, paket cermat, paket free servis, dan paket perawatan berkala. Dan dirutan kedua yaitu, Gt (ganti) dimana dalam hal servis ini hanya meliputi penggantian oli saja yaitu sebanyak 164 unit mobil. Di urutan selanjutnya LL (lain-lain) dimana dalam hal servis ini meliputi kerusakan yang jarang sekali dilakukan seperti v-belt, lampu, starter, dan lain-lain sebanyak 98 unit mobil. Berikutnya Pud (part update) yaitu perawatan yang mempunyai jangka waktu pembaharuan seperti SRS (Suplemental Restrain System) sebanyak 78 unit mobil. Dan yang terakhir yaitu BB (bunyi-bunyi) masalah bunyi yang sering timbul dikendaraan sebanyak 53 unit mobil.

\section{METODE}

Penggantian shock absorber pada mobil Honda CRV dikarenakan BB (bunyi-bunyi). Berikut langkah-langkah pengecekan dan penggantian shock absorber.

1) Berdasarkan WO (work order)

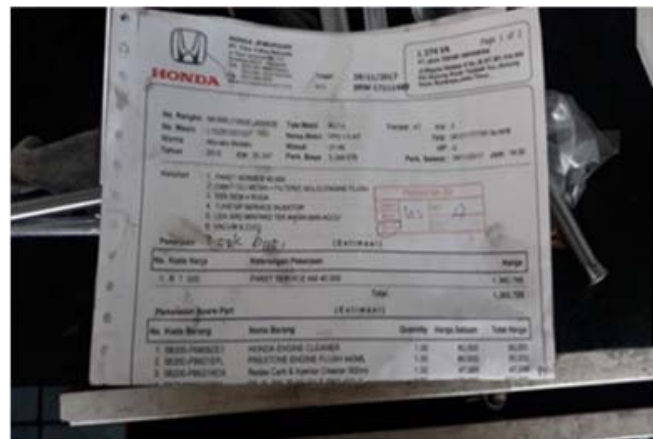

Gambar 5. WO (Work Order)
2) Memasang lift pada ke empat bagian.

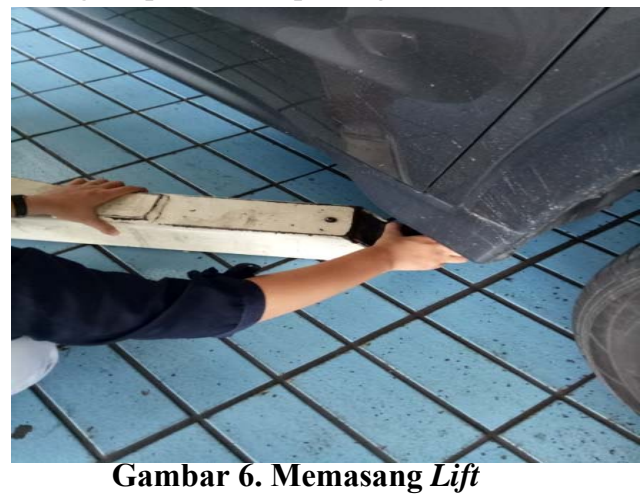

3) Menaikkan mobil secukupnya.

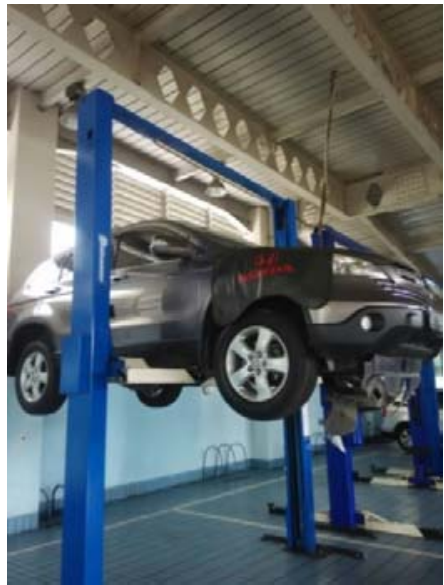

4) Mengecek bearing seluruh roda (apabila terjadi kerusakan, menuliskan pada lembar rekomendasi).

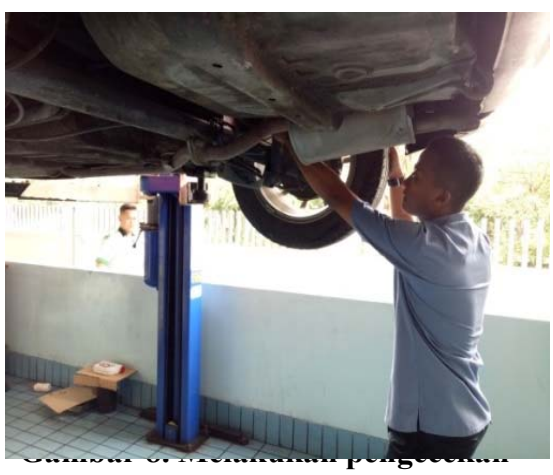

kondisi bearing roda

5) Mengecek shock absorber (apabila terjadi kerusakan, menuliskan pada lembar rekomendasi). 


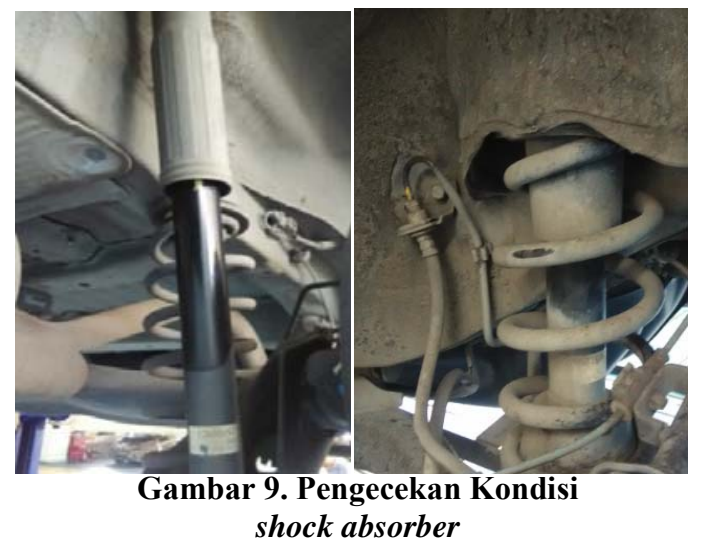

6) Melepas seluruh mur pengunci roda menggunakan impact dan kunci shock 19.

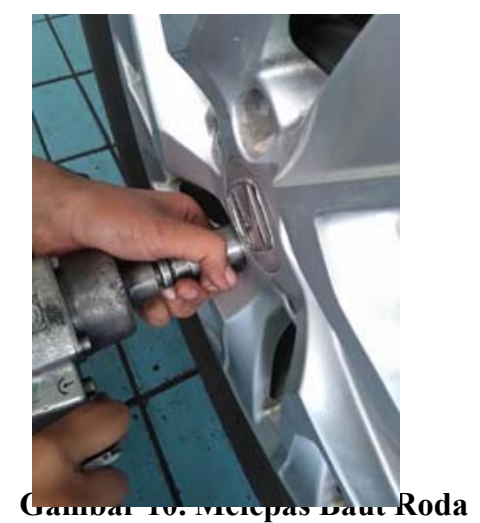

7) Melepas roda dari kendaraan

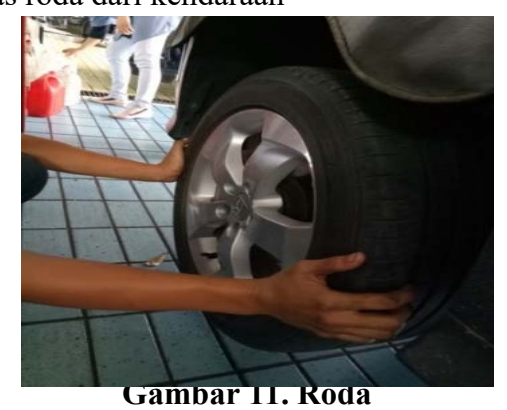

8) Lepaskan wheel sensor dan clip.

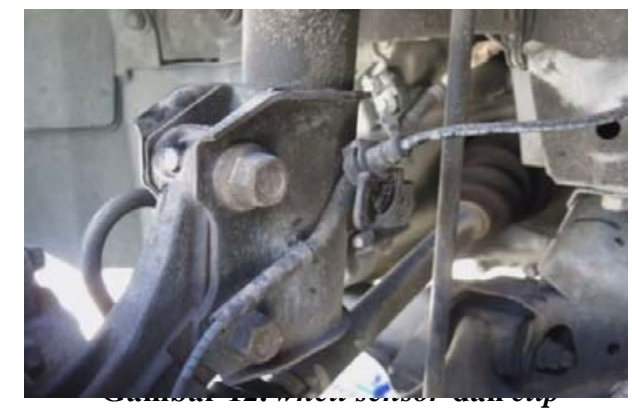

9) Lepaskan baut selang minyak rem menggunakan kunci 12

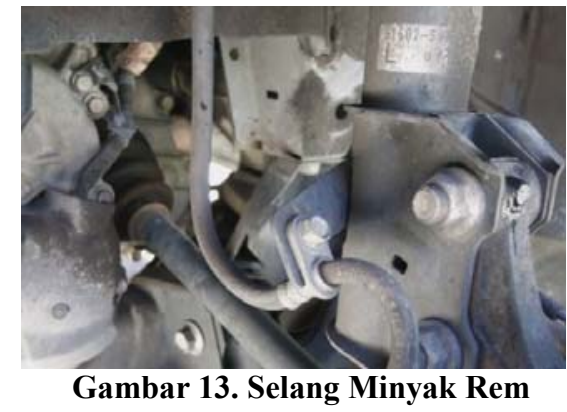

10) Lepaskan baut atas dan bawah link stabilizer menggunakan kunci 17

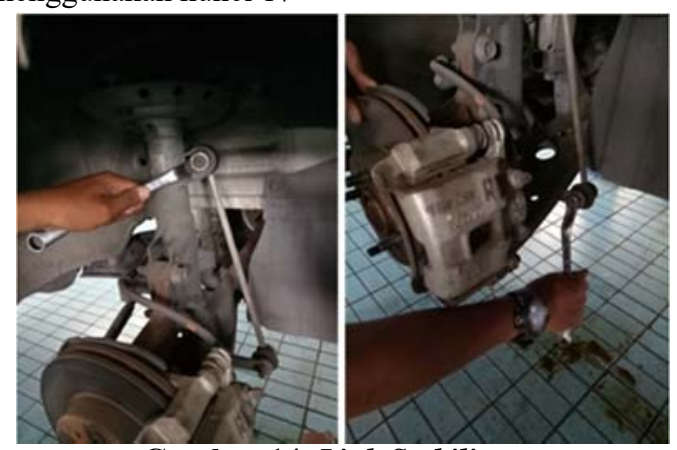

Gambar 14. Link Stabilizer

11) Lepaskan baut pinch bolt menggunakan kunci 19

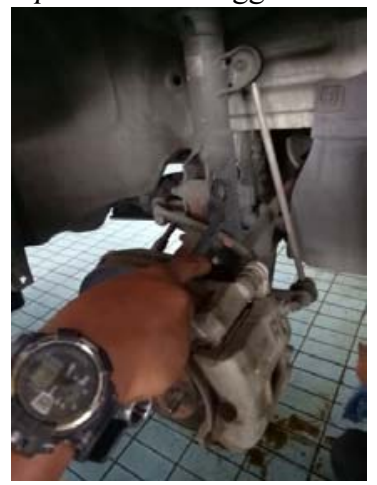

Gambar 15. Baut Pinch Bolt

12) Lepaskan cover bagian atas damper

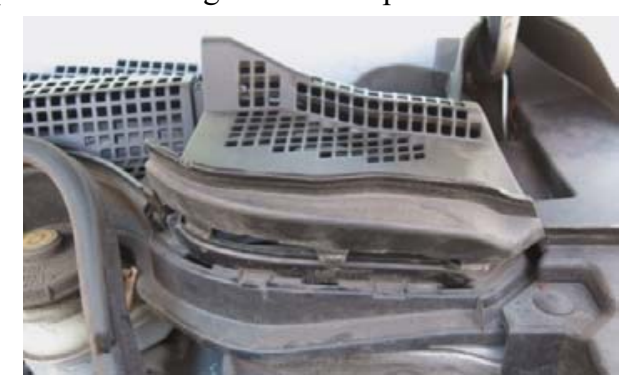

Gambar 16. Cover Bagian Atas Damper

13) Lepaskan baut flange bagian atas damper 


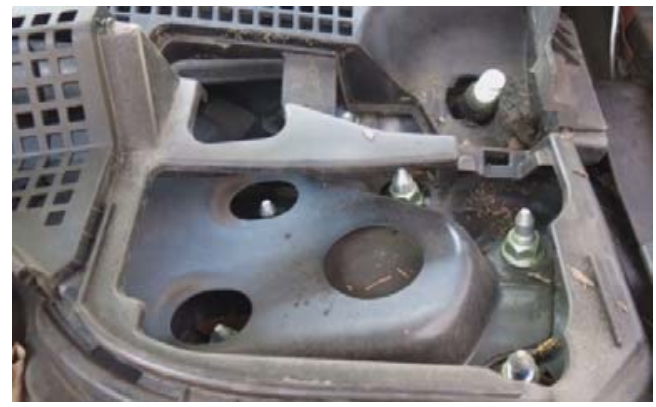

Gambar 17. Baut Flange Bagian Atas Damper

14) Lepas shock absorber dari body kendaraan

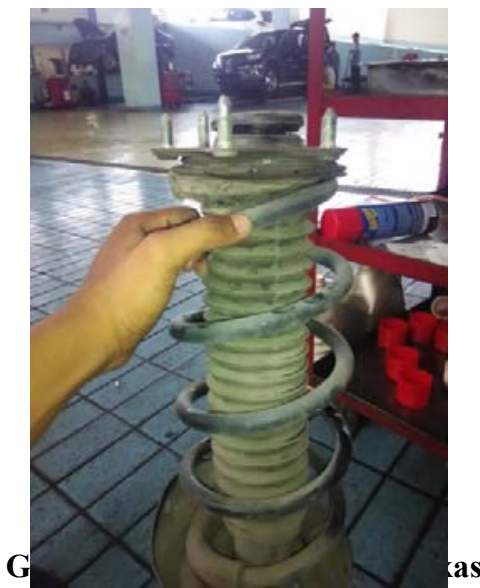

15) Siapkan shock absorber yang baru

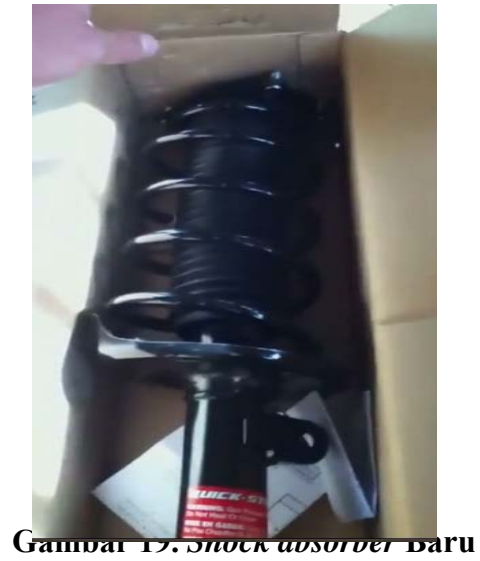

16) Langkah pemasangan shock absorber

(a) Pasang shock absorber yang baru pada bodi kendaraan (pasang shock absorber (A)), perhatikan arah damper mounting base agar tanda (B) mengarah ke sisi luar kendaraan.

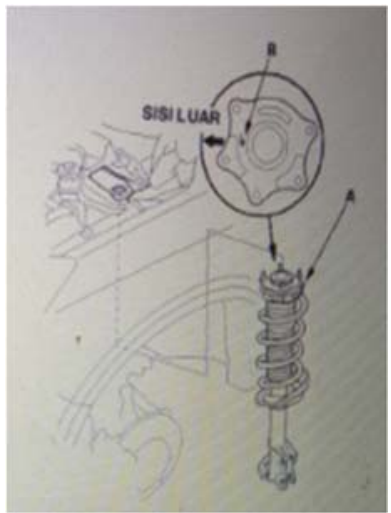

Gambar 20. Pemasangan Shock absorber

(b) Setelah shock absorber terpasang (pasang baut flange bagian atas damper, pasang baut pinch bolt, pasang link stabilizer, pasang selang minyak rem)

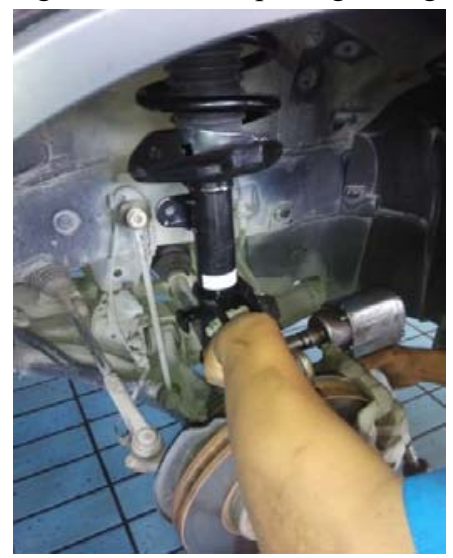

Gambar 21. Pemasangan Shock absorber

(c) Pasang roda kendaraan

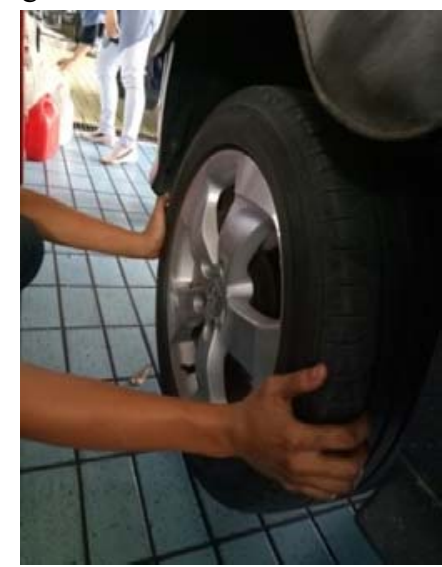

Gambar 22. Pemasangan Roda

(d) Pasang seluruh mur pengunci roda menggunakan impact dan kunci shock 19. 


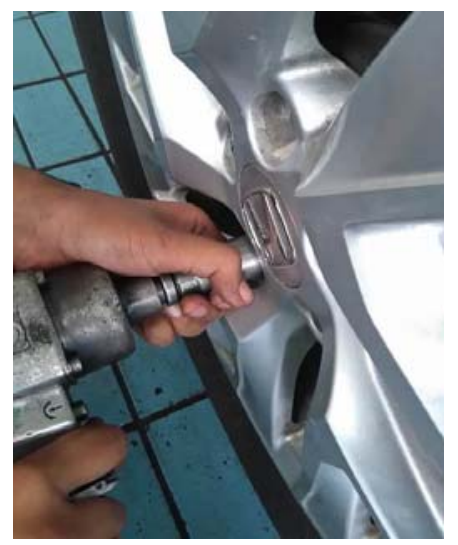

\section{DAFTAR PUSTAKA}

Anonim.(http://Mapelotomotif.Blogspot.Co.Id/2015/11/Mater i-Sistem-Suspensi Mobil.html di akses pada tanggal 24 November 2017)

PT. Citra Cakra Persada.2008. . Jakarta : Honda Prospect Motor Jakarta.

PT. Citra Cakra Persada Manual book Honda teknologi information

PT. Toyota Astra Motor.2012. Manual Book New Step 1 Training Manual

Manual Book Perbaikan Chasis Dan Pemindah Tenaga. Bandung : I solihin dan Mulyadi

Gambar 23. Memasang Baut Roda

(e) Contoh kerusakan shock absorber
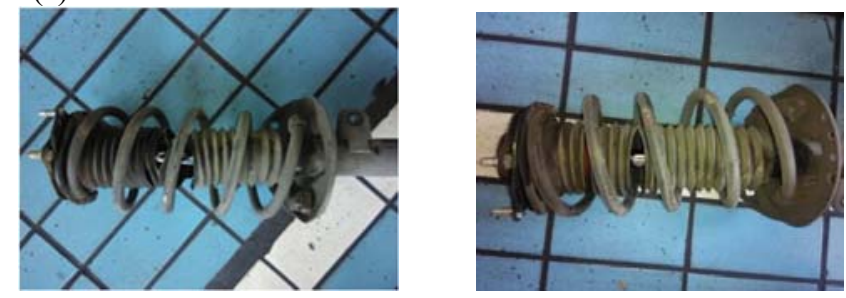

Gambar 29. Kerusakan pada Shock absorber

\section{SIMPULAN}

Berdasarkan hasil kegiatan diatas dapat diketahui bahwa proses penggantian shock absorber Honda CRV :

1) Honda CRV merupakan kendaraan tipe SUV (Sport Utility Vehicle) berjenis Front Engine Front Drive (FF) yang penempatan mesin dan roda penggerak utamanya berada di bagian depan. Ketika kecepatan tinggi kemudian ada proses pengereman maka beban terfokus pada satu titik yaitu didepan (penggerak depan). Sehingga daya cengkram semakin kuat berada antara roda dan bodi kendaraan terutama understell termasuk shock absorber.

2) Proses perawatan komponen-komponen suspensi terutama pada shock absorber dan bearing roda pada mobil Honda CRV termasuk pada paket perawatan berkala.

3) Penggantian shock absorber pada mobil Honda CRV dikarenakan BB (bunyi-bunyi) dalam kategori servis dengan 16 langkah pengerjaan.

4) Agar menghindari kerusakan yang lebih parah, monitoring dan perawatan rutin sesuai petunjuk dan kondisi penggunaan menjadi faktor penting agar komponen selalu mengalami kondisi prima. 